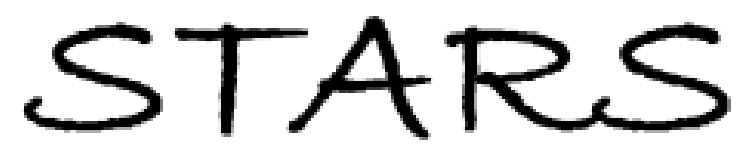

University of Central Florida

STARS

$1-1-2003$

\title{
Fabrication of air bridges using electron beam lithography
}

Michael A. Gritz

University of Central Florida

Meredith Metzler

Joel Moser

David Spencer

Glenn D. Boreman

University of Central Florida

Find similar works at: https://stars.library.ucf.edu/facultybib2000

University of Central Florida Libraries http://library.ucf.edu

This Article is brought to you for free and open access by the Faculty Bibliography at STARS. It has been accepted for inclusion in Faculty Bibliography 2000 s by an authorized administrator of STARS. For more information, please contact STARS@ucf.edu.

\section{Recommended Citation}

Gritz, Michael A.; Metzler, Meredith; Moser, Joel; Spencer, David; and Boreman, Glenn D., "Fabrication of air bridges using electron beam lithography" (2003). Faculty Bibliography 2000s. 3786.

https://stars.library.ucf.edu/facultybib2000/3786

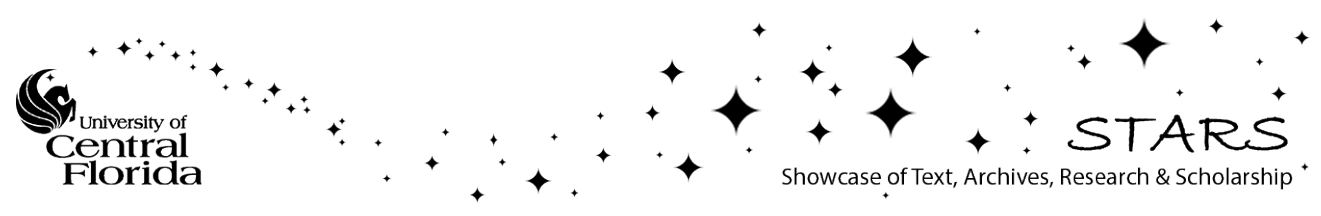




\section{Fabrication of air bridges using electron beam lithography}

Michael A. Gritz, Meredith Metzler, Joel Moser, David Spencer, and Glenn D. Boreman

Citation: Journal of Vacuum Science \& Technology B: Microelectronics and Nanometer Structures Processing, Measurement, and Phenomena 21, 332 (2003); doi: 10.1116/1.1539062

View online: https://doi.org/10.1116/1.1539062

View Table of Contents: https://avs.scitation.org/toc/jvn/21/1

Published by the American Institute of Physics

\section{ARTICLES YOU MAY BE INTERESTED IN}

Fabrication of metallic air bridges using multiple-dose electron beam lithography Applied Physics Letters 88, 202103 (2006); https://doi.org/10.1063/1.2204833

Fabrication of large dimension aluminum air-bridges for superconducting quantum circuits Journal of Vacuum Science \& Technology B 31, 031601 (2013); https://doi.org/10.1116/1.4798399

Fabrication and characterization of aluminum airbridges for superconducting microwave circuits Applied Physics Letters 104, 052602 (2014); https://doi.org/10.1063/1.4863745

Investigation into the charge distribution and barrier profile tailoring in AIGaN/GaN double heterostructures by self-consistent Poisson-Schrödinger calculations and capacitance-voltage profiling

Journal of Applied Physics 91, 4387 (2002); https://doi.org/10.1063/1.1459604

Direct three-dimensional patterning using nanoimprint lithography

Applied Physics Letters 78, 3322 (2001); https://doi.org/10.1063/1.1375006

Determination of heterojunction band offsets by capacitance-voltage profiling through nonabrupt isotype heterojunctions

Applied Physics Letters 46, 504 (1985); https://doi.org/10.1063/1.95572 


\title{
SHOP NOTES
}

These are "how to do it" papers. They should be written and illustrated so that the reader may easily follow whatever

instruction or advice is being given.

\section{Fabrication of air bridges using electron beam lithography}

\author{
Michael A Gritz ${ }^{\mathrm{a})}$ \\ School of Optics/CREOL, University of Central Florida, 4000 Central Florida Boulevard, Orlando, \\ Florida 32816-2700 \\ Meredith Metzler ${ }^{\text {b) }}$ \\ Cornell Nanofabrication Facility, Cornell University, Ithaca, New York 14853-5403 \\ Joel Moser ${ }^{\mathrm{c})}$ \\ Harvard Medical School, 25 Shattuck Street, Boston, Massachusetts 02115 \\ David Spencer ${ }^{\mathrm{d})}$ \\ Cornell Nanofabrication Facility, Cornell University, Ithaca, New York 14853-5403 \\ Glenn D. Boreman ${ }^{\mathrm{e}}$ \\ School of Optics/CREOL, University of Central Florida, 4000 Central Florida Boulevard, Orlando, \\ Florida 32816-2700
}

(Received 18 June 2002; accepted 25 November 2002; published 31 January 2003)

[DOI: $10.1116 / 1.1539062]$

\section{INTRODUCTION}

An area of radio frequency (rf) technology has emerged based on microelectromechanical systems (MEMS). A definition of a MEMS device is a miniature device or an array of devices combining electrical and mechanical components. ${ }^{1}$ MEMS devices are designed and fabricated by techniques similar to those of very large scale integration (VLSI) and can be manufactured by traditional batch processing methods. The ease of manufacture and the increased development of VLSI MEMS devices allow engineers to miniaturize sensors and transducers. One example of such an advancement is in the MEMS accelerometer, now one of the largest single MEMS applications with its incorporation in air bags. A rf MEMS device does not necessarily imply that the system is operating at $\mathrm{rf}$ frequencies. In many MEMS devices and components, the microelecromechanical operation is used simply for actuation or adjustment of another rf device. One example of such a device would be a variable capacitor or a simple switch.

For the air bridge shown in Fig. 1, the bottom metal contact forms a coplanar waveguide (CPW) transmission line. A rf switch has already been designed by using a distributed MEMS transmission line (DMTL). ${ }^{2}$ For DMTL, the air bridges over the center conductor are operated in a parallel configuration. When a bias voltage is applied to the center conductor of the CPW transmission line, charge distributes so that an electrostatic force occurs between the center conductor and the air bridge, which attracts the bridge down

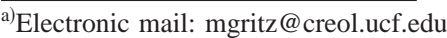

${ }^{b)}$ Electronic mail: metzler@cnf.cornell.edu

${ }^{c}$ Electronic mail: moser@cnf.cornell.edu

${ }^{d)}$ Electronic mail: spencer@cnf.cornell.edu

e)Electronic mail: boreman@creol.ucf.edu
}

toward the bottom contact. When the applied voltage reaches a threshold value $V_{\text {th }}$, the tensile force of the metallic air bridge can no longer withstand the electrostatic force, and the metal falls abruptly to the bottom contact. When the voltage is reduced, the metal bridge releases and returns to the original position. In Ref. 2, DMTL air bridges were fabricated using photoresist as the sacrificial layer, which is the layer removed toward the end of the fabrication process. The photoresist was removed by soaking the wafer in acetone. The wafer cannot be air dried because the surface tension of the liquid will pull the MEMS air bridges down. Therefore a critical point drying system is used to release the MEMS air bridges. ${ }^{3}$ A critical point drying system uses liquid $\mathrm{CO}_{2}$ to replace the solvent. $\mathrm{CO}_{2}$ is employed because when it is brought past its critical point the liquid immediately vaporizes into a gas, thus alleviating any surface tension from a solvent.

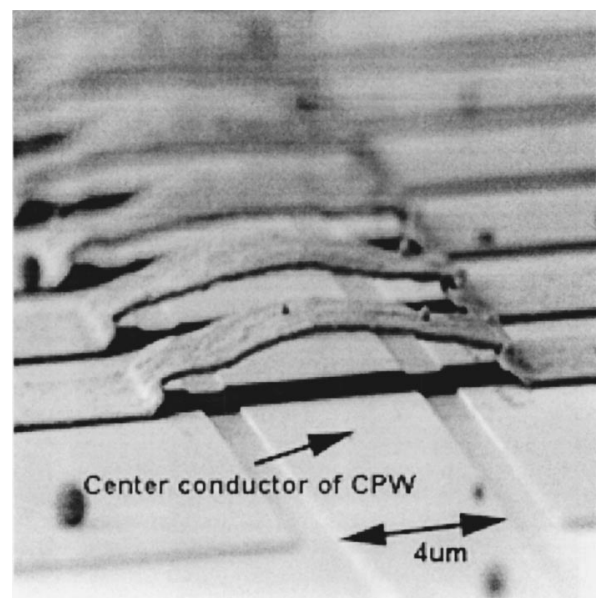

FIG. 1. SEM micrograph of an air bridge. 
In Ref. 2, a DMTL air bridge with a height of $1.5 \mu \mathrm{m}$ has been used as a true-time-delay phase shifter in the rf portion of the spectrum. The phase shift is accomplished by applying a single bias voltage to the center conductor of the CPW transmission line. The applied voltage causes the height of the MEMS bridges to be decreased, increasing the capacitive loading and decreasing the phase velocity. A major advantage to such a design is that only one control voltage is required. Our structure is a prototype for an infrared truetime-delay phase shifter. Using Refs. 2 and 4, an estimated bridge height of $0.5 \mu \mathrm{m}$ is required because a significantly smaller capacitance is required for use as an infraredfrequency phase shifter.

In this work, we will describe the electron beam (e-beam) lithography methods used to fabricate air bridges with a bridge height of $0.5 \mu \mathrm{m}$ without the need of a critical point dryer. In our system, poly (methyl methacrylate) (PMMA) was chosen as the sacrificial layer. The PMMA was removed with oxygen plasma using a Branson barrel etcher as an isotropic reactive ion etcher (RIE). The major advantage to our method is in the simplification of the fabrication for the air bridges. By avoiding the critical point dryer, the PMMA sacrificial layer can be etched away without any concern regarding maintenance of the proper solvent surface tension. Because our system uses PMMA as the sacrificial layer, which is a high resolution e-beam resist, this allows for the possibility of fabricating nano-DMTL air bridges.

\section{FABRICATION AND RESULTS}

The air bridges were fabricated at the Cornell Nanofabrication Facility using a Cambridge/Leica EBMF 10.5 e-beam lithography system, with an on-chip resolution of $0.1 \mu \mathrm{m}$. On each $10 \mathrm{~mm}$ by $10 \mathrm{~mm}$ Si chip ten devices were written with a $730 \mu \mathrm{m}$ center-to-center spacing. Each DMTL device had 26 air bridges with a center-to-center spacing of $15 \mu \mathrm{m}$. The dimensions of the bridges were $8 \mu \mathrm{m}$ long by $8 \mu \mathrm{m}$ wide, which is shown in Fig. 2. There were four separate layers which were fabricated in the following order:

(1) alignment marks,

(2) CPW transmission lines,

(3) PMMA sacrificial layer, and

(4) Au bridge.

The first step in the fabrication process was to write a set of alignment marks. The alignment marks were made of $\mathrm{Au}$ because the EBMF uses a backscatter detector to detect secondary electrons for precise alignment, which means that an element with a high $Z$ number is more effective.

Both local and global alignment marks were written. The global marks were used to correct for any rotation errors while loading the substrates into the chuck, while the local marks were used to correct for any stage drift when moving from field to field. By using the two sets of alignment marks extremely precise alignment was possible. A similar alignment scheme was employed in Ref. 5, which had an overlay accuracy of less than $100 \mathrm{~nm}$. Another alignment scheme used high contrast alignment marks, which were fabricated by RIE into $\mathrm{Si}^{6}{ }^{6}$ For our alignment scheme, the thickness of

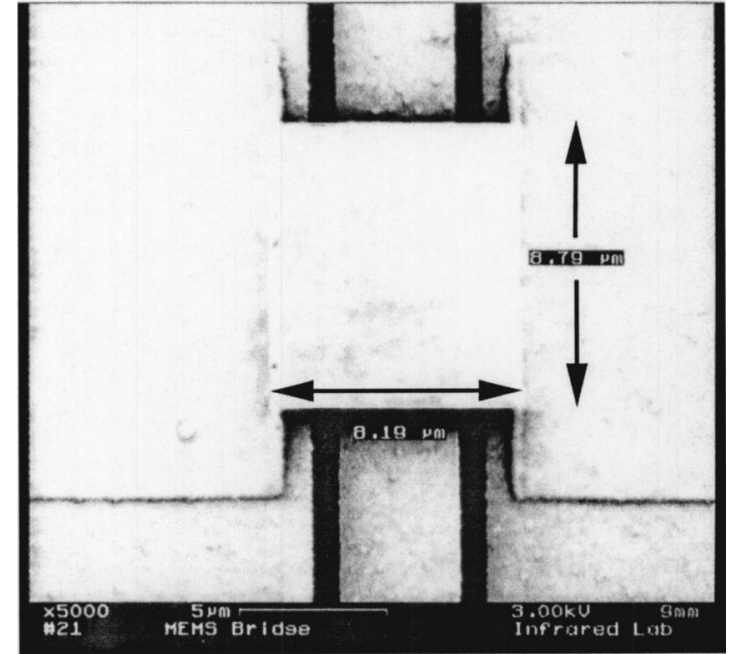

FIG. 2. Schematic of a single DMTL air bridge with dimensions of $8 \mu \mathrm{m}$ by $8 \mu \mathrm{m}$.

the $\mathrm{Au}$ was varied to find the best overlay accuracy. We found the overlay accuracy to be better than $25 \mathrm{~nm}$ when 250 $\mathrm{nm}$ of Au was used.

The next step is the fabrication of the CPW transmission lines, which are the bond pads and the center conductor of the CPW [see Fig. 3(a)]. The width of the center conductor is $4 \mu \mathrm{m}$ with $1 \mu \mathrm{m}$ gaps. These dimensions were chosen for a design capacitance of $20 \mathrm{fF}$ in the unbiased state. The process used to fabricate the CPW transmission lines was a traditional liftoff process using a bilayer resist profile. First PMMA-MAA was spun onto the wafer at $3000 \mathrm{rpm}$, which has a higher sensitivity. The substrates were baked on a hotplate set to $170{ }^{\circ} \mathrm{C}$ for $10 \mathrm{~min}$ to remove any solvents. Using an interferometer the resist thickness was measured at 305 $\mathrm{nm}$. After the resist thickness was measured, the second layer was spun onto the substrates. For this layer PMMA was spun onto the substrates at $3500 \mathrm{rpm}$. Next the substrates were baked on a hotplate set to $170^{\circ} \mathrm{C}$ for $10 \mathrm{~min}$. This yielded a total resist thickness of $460 \mathrm{~nm}$. The patterns were written at a beam current of $30 \mathrm{nA}$ with a dose of $150 \mu \mathrm{C} / \mathrm{cm}^{2}$. After the exposure, the substrate was developed in methylisobutylketone (MIBK):isopropyl alcohol (IPA) 1:1 for $1 \mathrm{~min}$. After development the substrates were rinsed with isopropanol and dried with $\mathrm{N}_{2}$. The next step was to remove any unwanted resist, which may have been left behind after the development but not seen under an optical microscope. Any such resist layer was removed by oxygen plasma in a Branson barrel etcher. ${ }^{7}$ This was done each time immediately after the development of the substrates. After the development and the oxygen plasma cleaning of the substrates, a $10 \mathrm{~nm}$ thick adhesion layer of titanium and a $100 \mathrm{~nm}$ thick layer of $\mathrm{Au}$ was e-beam evaporated onto the substrate. The unwanted resist and metallic films were lifted off using methylene chloride.

The next step in the fabrication process was to fabricate the PMMA sacrificial layer [see Fig. 3(b)]. This is accomplished by first exposing the area where the Au bridge is desired, which will pattern the base of the bridge. The di- 


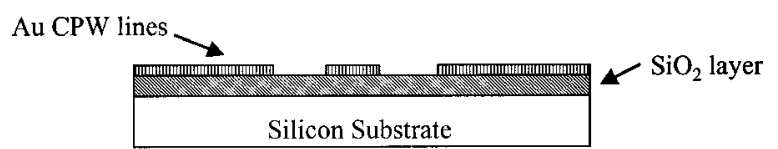

a)

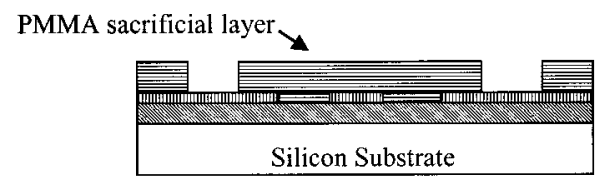

b)
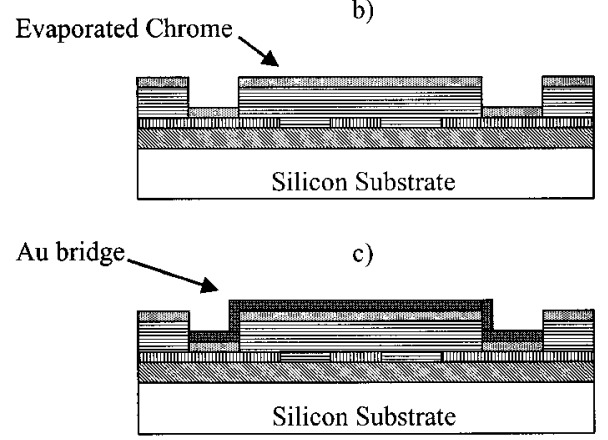

d)

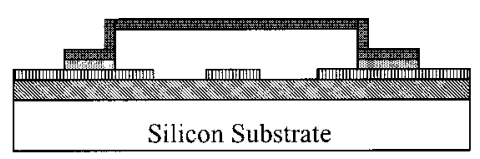

e)

FIG. 3. Details of the fabrication process for the air bridges.

mensions for the base of the bridge were $8 \mu \mathrm{m}$ by $8 \mu \mathrm{m}$. Then the PMMA is overexposed, which causes the resist to crosslink, in the area where the PMMA will act as the sacrificial layer. The dimensions for the sacrificial layer were 8 $\mu \mathrm{m}$ by $400 \mu \mathrm{m}$. In order to accomplish this, PMMA resist was spun on the wafer at $3000 \mathrm{rpm}$. The substrates were baked on a hotplate set to $170{ }^{\circ} \mathrm{C}$ for $10 \mathrm{~min}$ to remove any solvents. Using an interferometer the resist thickness was measured at $550 \mathrm{~nm}$. The first set of patterns, which were the base of the bridges, was written at a beam current of $30 \mathrm{nA}$ with a dose of $200 \mu \mathrm{C} / \mathrm{cm}^{2}$. The next set of patterns, which is the sacrificial layer, was written at a beam current of $30 \mathrm{nA}$ with a dose of $10000 \mu \mathrm{C} / \mathrm{cm}^{2}$. After the exposures, the substrate was developed in MIBK:IPA 1:1 for $2 \mathrm{~min}$. After the development, an oxygen plasma etch was performed for 1 min. Then a $50 \mathrm{~nm}$ layer of chromium was thermally evaporated onto the substrate to help protect the PMMA from being washed away by the acetone during the liftoff process of the gold bridge [see Fig. 3(c)].

The final step in the fabrication of the air bridges is to create the $\mathrm{Au}$ bridge on top of the PMMA sacrificial layer using a liftoff process [see Fig. 3(d)]. First PMMA (PMMAMAA) resist was spun onto the wafer at $3500 \mathrm{rpm}$. The substrates were baked on a hotplate set to $115^{\circ} \mathrm{C}$ for $30 \mathrm{~min}$. The temperature was lowered to $115^{\circ} \mathrm{C}$ because both PMMA and PMMA-MAA will re-flow at approximately $120^{\circ} \mathrm{C}$. Using an interferometer the resist thickness was measured at $560 \mathrm{~nm}$. After the resist thickness was measured, the second layer was spun onto the substrates. For this layer PMMA was spun onto the substrates at $3500 \mathrm{rpm}$. Next the substrates were baked on a hotplate set to $115^{\circ} \mathrm{C}$ for $30 \mathrm{~min}$. This yielded a total resist thickness of $761 \mathrm{~nm}$. The patterns were written at a beam current of $30 \mathrm{nA}$ with a dose of $200 \mu \mathrm{C} / \mathrm{cm}^{2}$. The substrate was developed in MIBK:IPA 1:1 for $2 \mathrm{~min}$. After an oxygen plasma etch was performed for 1 min, $10 \mathrm{~nm}$ of chromium and $250 \mathrm{~nm}$ of Au was e-beam evaporated onto the substrates. The unwanted resist and metallic films were lifted off using acetone. Acetone was preferable to methylene chloride because methylene chloride was found to be too aggressive. Next the substrates were placed in a chrome etchant for $20 \mathrm{~s}$ to remove the chromium layer.

Once the chromium was removed, a resist strip was done using oxygen plasma on a Branson barrel etcher [see Fig. $3(\mathrm{e})$ ]. A barrel etcher is an isotropic etch, which means it etches equally in all directions. The etch time was set to 4 min in order to ensure that all the PMMA under the Au bridge was etched away. After the etching of the PMMA, the air bridges were examined using a scanning electron microscope (SEM). Micrographs taken from the SEM can be seen in Fig. 1, clearly indicating an air bridge.

\section{SUMMARY}

The fabrication of air bridges has been demonstrated using electron beam lithography using PMMA as the sacrificial layer. PMMA has a high resolution when used as an e-beam resist. This process provides the possibility for fabrication of nano-MEMS air bridges. Furthermore this work demonstrates the fabrication of air bridges with a Branson barrel etcher instead of a critical point dryer, which significantly advances the ease of fabrication for MEMS devices in general. This process could be developed to allow for MEMS tuners, MEMS passive elements, or MEMS phase shifters to be monolithically integrated onto the same chip.

\section{ACKNOWLEDGMENTS}

This work was performed in part at the Cornell Nanofabrication facility (a member of the National Nanofabrication Users Network), which is supported by the National Science Foundation under Grant No. ECS-9731293, Cornell University, and industrial affiliates. This material is based upon research supported by NASA Grant No. NAG5-10308.

${ }^{1}$ J. Bryzek, K. Peterson, and W. McCulley, IEEE Spectrum May, 20 (1994).

${ }^{2}$ N. S. Barker and M. G. Rebeiz, IEEE Trans. Microwave Theory Tech. 2, 1881 (1998).

${ }^{3}$ G. T. Mulhern, D. S. Soane, and R. T. Howe, International Conference on Solid-State Sensors and Actuators, June 1993, Vol. 296.

${ }^{4}$ C. Fumeaux, M. A. Gritz, I. Codreanu, W. L. Schaich, F. J. González, and G. Boreman, Infrared Phys. 41, 271 (2000).

${ }^{5}$ C. A. Berseth, B. Dwir, I. Utke, H. Pier, A. Rudra, V. P. Iakovlev, and E. Kapon, J. Vac. Sci. Technol. B 17, 3222 (1999).

${ }^{6}$ M. N. Webster, A. H. Verbruggen, H. Jos, J. Romijn, P. M. A. Moors, and S. Radelaar, Microelectron. Eng. 17, 37 (1992).

${ }^{7}$ M. N. Webster et al., Microelectron. Eng. 23, 441 (1994). 